\title{
LATÍN JURÍDICO, ETIMOLOGÍAS Y ALGO MÁS: EL LATÍN EN NUESTRA PRENSA
}

\author{
Henry Campos Vargas
}

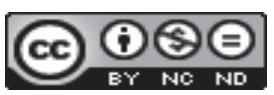

Esta obra está bajo una licencia Creative Commons

Reconocimiento-No Comercial-Sin Obra Derivada 



\title{
LATÍN JURÍDICO, ETIMOLOGÍAS Y ALGO MÁS: EL LATÍN EN NUESTRA PRENSA
}

\section{LEGAL LATIN, ETYMOLOGIES, AND SOMETHING ELSE: LATIN IN OUR PRESS}

\author{
Henry Campos Vargas
}

\begin{abstract}
RESUMEN
En el presente artículo, se clasifican distintas expresiones latinas, aparecidas en algunos periódicos costarricense entre abril y octubre, ambos del 2004.

Palabras clave: latín, latín jurídico, latín cristiano, uso del latín, latín periodístico.
\end{abstract}

\section{ABSTRACT}

This paper classifies in some categories latin expressions appeared in some newspaper in Costa Rica from April 2004 to October 2004.

Key words: latin, legal latin, christian latin, use of the latin, latin in newspapers.

A don Víctor Sánchez, gracias por su ejemplo de laboriosidad y honestidad.

\section{Introducción}

El latín es una realidad lingüística que nos acompaña cada día. Continuamente es usado por gran cantidad de periodistas, ensayistas y columnistas nacionales.

Este trabajo considera un corpus de latinismos aparecidos en los diarios Extra y La Nación entre el 12 de abril y el 27 de octubre, ambos del 2004. Fueron identificadas 109 entradas de frases, locuciones o citas latinas de muy diversa índole.

ML. Henry Campos Vargas. Universidad de Costa Rica. Profesor de la Escuela de Filología, Lingüística y Literatura. Costa Rica.

Correo electrónico: hcamposv@yahoo.es

Recepción: 20- 02- 2014

Aceptación: 18- 03- 2014 


\section{Latín jurídico}

Uno de los principales registros que presenta el corpus seleccionado es el correspondiente al latín jurídico, que junto con el estudio de las etimologías y fraseología en general, representan los ámbitos de mayor incidencia en su uso. En estos ricos campos encontramos voces comunes del latín clásico, pero con una semántica particular. Por su naturaleza, cabe destacar que no pocas veces aparece asociado al ámbito político, tal y como podrá apreciar el lector en las siguientes muestras

a limine (Rodríguez, 11/06/2004)

desde la entrada, desde el inicio, frase preposicional aplicada a las decisiones o actos tomados el inicio de un procedimiento. Es la forma abreviada de a limine litis, desde el inicio del proceso.

ad honorem/ad honores (Editorial de La Nación, 14/06/2004; Guardia, 15/06/2004; Salas, 20/06/2004; López, 28/09/2004)

por el honor/por los honores, locución que califica los cargos que se desempeñan sin contraprestación económica, es decir, en la mentalidad romana (¿y, por qué no?, moderna) el solo honor de cumplir con el puesto era retribución más que suficiente.

ad portas (Urbina, 29/09/2004)

a las puertas, en la puerta, locución empleada para caracterizar los actos que deben ser rechazados sin necesidad de trámite o audiencia alguna.

animus (Marín, 12/04/2004)

ánimo, intención, en el derecho es uno de los presupuestos subjetivos de gran cantidad de actos, tanto en el derecho civil, como el comercial, laboral e, incluso, el penal.

animus abutendi (Marín, 12/04/2004)

intención de abusar, identifica el exceso en el ejercicio de una determinación situación jurídica.

animus doli (Marín, 12/04/2004)

intención de dañar, se refiere al presupuesto subjetivo que permite establecer una relación de responsabilidad legal de un sujeto frente a un resultado dañoso.

animus injuriandi (Marín, 12/04/2004)

intención de injuriar, presupuesto subjetivo de los delitos de injurias, calumnia o difamación.

animus iocandi (Marín, 12/04/2004)

ánimo de bromear, neologismo formado a partir de los anteriores ejemplos usado para referirse a aquellos actos en los que un sujeto no tiene la intención de producir el acto que ejecuta de acuerdo con las reglas de la pragmática, por cuanto se trata de una broma.

\section{Carta Magna (EKA, 10/05/2004)}

Carta Magna, denominación del documento otorgado por el Rey Juan en el año 1215. Por antonomasia se aplica a toda Constitución Política moderna. 
conditio sine qua non (EKA, 10/05/2004)

condición necesaria, condición sin la cual no, préstamo del latín propio de la argumentación y la lógica de uso frecuente en el campo del derecho.

contratio sensu (09/06/2004)

en sentido contrario, frase del ámbito de la lógica de empleo muy generalizado en el derecho. Consiste en negar una tesis planteada explícitamente en una norma jurídica para identificar sus posibles consecuencias con un valor argumentativo.

de facto (Editorial, La Nación, 19/07/2004)

de hecho, dícese del gobierno establecido y actuante sin respaldo en una norma constitucional preexistente reconocida, esto en oposición al denominado gobierno de iure, de derecho.

exceptio veritatis (Vizcaíno, 06/05/2004)

la excepción de la verdad, defensa propia de las acusaciones por delitos contra el honor según la cual quien ha afirmado algo que se acusa como injurioso, por ejemplo, demostrará que no cometió delito alguna si comprueba que lo afirmado era verdadero.

honoris causa (EFE, 11/05/2004)

por honor, por lo general se aplica a aquellos títulos o reconocimientos otorgados en atención a la trayectoria, aportes, dedicación o prestigio de una persona en determinado campo del saber, la ciencia, la técnica o el arte, entre otros.

in absentia (Chaves, 02/05/2004)

en ausencia, se aplica a aquellos procedimientos judiciales seguidos contra acusados que se encuentran en fuga. En Costa Rica, tal tipo de procedimientos está prohibido constitucionalmente.

in situ (Rodríguez, 26/06/2004)

en el sitio, dícese de los actos realizados fuera de los espacios institucionales para que, a través de la inmediación, es decir, el contacto inmediato de la autoridad con personas, lugares, contextos... lograr una mejor solución a un conflicto.

inter alia (Echeverría, 10/08/2004)

entre otros, frase empleada para contextualizar la relaciones jurídicas establecidas en el marco de un determinado sistema normativo.

jus standi (Niehaus, 29/06/2004)

derecho de estar, en el derecho procesal internacional público alude al eventual derecho de ser tenido como sujeto procesal en un procedimiento de esta índole. La $j$ se debe a la grafía renacentista seguida por el autor del artículo.

lapsus mentis (Díez, 25/07/2004)

desliz de la mente, sintagma usado para disculpar un error de pensamiento, el cual se atribuye a un descuido momentáneo de la mente.

locus standi (Niehaus, 29/06/2004)

posición de estar, expresión del derecho procesal internacional público para identificar la participación de los individuos en las distintas etapas del proceso. 
modus operandi (Garnier, 09/09/2004)

modo de operar, modo de actuar, expresión propia de la jerga de los penalistas, usada para describir la conducta investigada.

motu proprio (Niehaus, 29/06/2004)

por movimiento propio, por iniciativa propia, expresa la capacidad y libertad de ejercer un determinado derecho.

pater familias (Valembois, 27/05/2004)

padre de familia, denominación aplicada a la máxima autoridad romana en una gens. De acuerdo con el derecho romano, era el varón romano libre de mayor edad en el grupo familiar. Sus funciones y poderes variaron a través del tiempo, llegando en un momento a detentar el ius necis uitaeque, el derecho sobre la vida y la muerte de los filii familias. El sintagma presenta un genitivo sigmático de origen arcaico que se ha mantenido petrificado hasta el día de hoy.

pro (Gerard, 10/05/2004)

a favor de, esta preposición no es de uso exclusivamente legal, pues pertenece al latín cotidiano. No obstante, su uso en la actualidad tiene lugar en contextos jurídicos atinentes a reivindicaciones de las más distinta naturaleza que comprenden desde aspectos ecológicos, hasta el derecho penal.

sicarius (Rodríguez, 24/05/2004)

asesino, sustantivo perteneciente al ámbito del derecho penal.

statu quo (Sojo, 29/04/2004, La Nación, Editorial, 28/09/2004)

el estado en que se encuentra(n), es un latinismo de uso muy extendido para aludir al conjunto de condiciones que prevalecen en un momento histórico determinado.

Marca un predominio el empleo del latín para identificar la etimología de las palabras. status libertatis (Bertozzi, 27/10/2004)

Estado de libertad, dícese de quien ostenta la condición de persona libre en una comunidad política.

status civitatis (Bertozzi, 27/10/2004)

Estado de ciudadanía, se aplica para distinguir la condición política de un ciudadano en su ciudad.

status familiae (Bertozzi, 27/10/2004)

Estado de familia, se emplea para identificar la posición de un individuo en su núcleo familiar.

Estos tres latinismos fueron empleados en el mismo texto, donde aparecen negados, para destacar la condición de igualdad entre las personas.

\section{Latín cristiano}

Aunque breve en este corpus, la contribución del latín cristiano aparece continuamente en nuestro medio, tal y como se puede apreciar a continuación. 
corpus (Mendoza, 13/06/2004)

cuerpo, si bien esta voz es de uso extendido en el ámbito del derecho, también identifica una importante festividad católica, la del Corpus Christi, el Cuerpo de Cristo, en la que se celebra la institución del sacramento de la eucaristía.

in extremis (Sojo, 15/08/2004; Rodríguez, 08/10/2004)

en el último momento, se refiere particularmente al momento de la muerte o a la última oportunidad de realizar un acto en determinado contexto.

mea culpa (Varela, 17/10/2004)

por mi culpa, frase empleada para reconocer algún grado de culpabilidad en un evento.

Opus Dei (Jiménez, 15/08/2004)

La obra de Dios, denominación de una prelatura personal católica.

ora pro nobis (Díaz, 08/05/2004)

ruega por nosotros, expresión empleada en la liturgia latina de la misa. En la versión latina del rosario, respuesta que dan los circunstantes a cierto grupo de letanías.

Urbi et orbi (Murillo, 08/05/2004; Rivera, 10/05/2004; Rossi, 20/10/2004)

a la ciudad y al mundo, frase que identifica cierto tipo de pronunciamientos del Papa. Apareció usada no en este contexto, sino en relación con la política de la Casa Blanca en la guerra contra Iraq, así como en materia de piratería contra empresas transnacionales.

\section{Latín etimológico}

Un importantísimo ámbito de uso del latín es el de la etimología. Su estudio permite fijar la ortografía de numerosas palabras, así como comprender el sentido de las palabras, así como su evolución ante cambios semánticos y léxicos.

adolescentem (López, 02/09/2004)

adolescente, participio latino que da origen a esta voz en español

adolescer (López, 02/09/2004)

crecer, de su participio pasivo procede adolescente.

adultus (López, 02/09/2004)

adulto, adjetivo del que se deriva el sustantivo adulto en nuestra lengua.

ager, agri (Díez, 12/09/2004)

campo de cultivo, citado a propósito de un reflexión sobre los cultivos.

assectari (Díez, 07/06/2004)

perseguir, verbo latino del que proceden acechar y asechar.

calculus (Fernández, 12/04/2004)

piedrecita, cálculo, voz muy usada en matemática.

claviculi (Fernández, 12/04/2004)

clavillos, nombre dado por los romanos a las pequeñas cuentas de sus instrumentos de conteo. 
esse (Díez, 03/10/2004)

ser.

exigere (López, 03/06/2004)

exigir, verbo latino del que deriva el adjetivo exiguus.

exiguitas (López, 03/06/2004)

brevedad, sustantivo latino abstracto derivado de exiguus.

exigue (López, 03/06/2004)

brevemente, adverbio latino procedente de exiguus.

exiguo (López, 03/06/2004)

brevemente, adverbio latino formado a partir de exiguus.

exiguus (López, 03/06/2004)

exiguo, adjetivo latino del que deriva exiguo.

colere (Díez, 12/09/2004)

cultivar, voz latina de la cual derivan numerosas palabras del español.

competere (López, 29/06/2004)

competer, verbo latino del cual proceden los verbos competir y competer.

cum (López, 29/06/2004)

con, preposición latina que, en composición con peter, da lugar al verbo competere.

donarium (López, 27/10/2004)

ofrenda, altar, a través del latín medieval posible origen de donaire.

fugi (Díez, 03/10/2004)

hui, posible etimología de fui, de ir.

hoc die (López, 08/09/2004)

en este día, origen etimológico de la palabra hoy.

incunabula (López, 01/07/2004)

lugar de la cuna, de esta voz deriva incunable.

iners, inertis (López, 29/09/2004)

sin energía, etimología de inercia.

inertia (López, 29/09/2004)

inercia, derivado etimológico de inertes.

leoginem (López, 08/06/2004)

Sustantivo latino del que posiblemente se origine el topónimo León.

leonem (López, 08/06/2004)

león, étimo del que proviene la palabra león.

mentha/mintha (López, 27/10/2004)

menta, nombre de una planta de consumo muy popular. 
nares/naris (López, 09/09/2004)

nariz, etimología de esta parte de la anatomía humana.

naricem/narices (López, 09/09/2004)

nariz, voz del latín vulgar de donde se origina su correspondiente derivado en español.

petere (López, 29/06/2004)

pedir, verbo latino que, en composición con la preposición cum, da lugar al verbo competere.

pulegium/puleium (López, 26/10/2004)

poleo, hierba aromática, es citada a propósito de una reflexión etimológica.

sica (Rodríguez, 24/05/2004)

puñal, en español no sobrevive esta palabra sino a través de su derivado sicario.

torta (López, 24/05/2004)

torta, voz del latín tardío del cual se deriva su homónimo en español.

\section{Latín científico}

Este registro del latín ha permitido que esta lengua se mantenga "viva" en nuestros tiempos, ya que permanentemente se incorporan nuevas voces para identificar las especies de más reciente descubrimiento.

archaeocyon leptodus (A.P., 03/10/2004)

Antepasado de los perros modernos.

cattleya labiata (Ossenbach, 15/06/2004)

Nombre científico de la primera guaria llevada en 1818 a Inglaterra por William

Cattley desde Brasil.

cattleya skinneri (Ossenbach, 15/06/2004)

Nombre científico anterior de la Guaria Morada, Flor Nacional de Costa Rica.

epicyon haydeni (A.P., 03/10/2004)

Nombre de un antepasado de los perros modernos.

guarianthe skinneri (Ossenbach, 15/06/2004)

A partir del 2003, nombre científico actual de la flor anteriormente denominada cattleya labiata, nuestra Guaria Morada.

papaver somniferum (Ponchner, 29/09/2004)

Nombre científico de la planta de la amapola del opio.

Sigmatostalix unguiculata (Ossenbach, 20/05/2004)

Nombre científico de una orquídea descubierta por Alexander F. Skutch en Costa Rica.

\section{Latín paródico}

No podía faltar la imitación burlesca del latín, ya en sus rasgos fónicos característicos, ya en expresiones de conocimiento general. 
sexus benedictus (Díaz, 30/04/2004)

bendito sexo, título de una obra de teatro costarricense en la que muta aquella visión que tiende a ver el sexo como una maldición y fuente de condenación para hombres y mujeres.

stupidare humanum est (Bolaños, 20/06/2004)

la estupidez es humana, derivado de la máxima errare humanum est, errar es humano.

\section{Fraseología latina}

Igualmente figuran no pocos latinismos que no pertenecen a ninguna área en específico. A este grupo pertenecen frases, giros, expresiones de transición, etcétera, que adornan el discurso y facilitan su lectura.

ante portas (Bada, 03/10/2004)

ante las puertas, aplícase para expresar la proximidad de un evento.

Carmina burana (Quirós, 05/05/2004)

Cármina burana, nombre de una famosa composición musicial de Karl Orff.

carpe diem (Hurtado, 19/09/2004)

aprovecha el día, máxima horaciana que exhorta a no desperdiciar ningún momento de nuestra vida.

Chronicus morbus est (Durán, 04/07/2004)

es una enfermedad crónica, título de un artículo de Fernando Durán Ayanegui.

data (Varela, 14/10/2004)

datos, fecha, frase nominal con valor temporal.

De profundis (Sánchez, 27/08/2004)

desde las profundidades, acerca de lo profundo, nombre de una obra homónima de Federico García Lorca.

déficit (Editorial, González, 04/05/2004)

falta, verbo latino que en español se ha degradado a sustantivo para emplearse en el ámbito económico.

dicit (Hurtado, 24/10/2004)

dice, verbo que permite la introducción de manera elegante de una cita o frase atribuida a determinado autor.

hábitat (Flury, 19/05/2004)

él habita, él vive, en español esta oración latina se ha degradado a sustantivo referido al entorno en el que vive un miembro, ya de la flora, ya de la fauna.

homo sapiens (Hess, 11/05/2004; Murillo, 13/05/2004)

hombre sabio, nombre científico de los seres humanos.

honor et onus (Rodríguez, 05/05/2004)

un honor y una responsabilidad, aplícase a aquellos cargos de gran responsabilidad que son otorgados en atención a los méritos de la persona designada. 
humus (Trigueros, 11/09/2004)

suelo, hace referencia al suelo como productor y generador de cultivos.

id est (Rivera, 05/05/2004)

eso es, sentencia de carácter explicativo usada en el curso de un texto.

ipso facto (Sánchez, 24/10/2004)

en el mismo acto, en el mismo momento, frase adverbial que expresa simultaneidad de entre dos o varios acciones.

Legio Septima Pia Felix (López, 08/06/2004)

Nombre de una legión romana.

massa (Sagot, 26/08/2004)

montón, empleado para referirse despectivamente a una colectividad.

mutatis mutandi (Durán, 04/07/2004)

cambiando lo que se debe cambiar, frase empleada en construcciones analógicas o ejemplos para salvar las diferencias entre los factores que se comparan.

post mortem (Flury, 19/05/2004)

después de la muerte, aplícase para referirse a eventos posteriores al deceso de una persona.

quid (Rodríguez, 29/09/2004)

el qué, se refiere al objeto o tema de una discusión.

quid pro quo (Urbina, 06/05/2004; Díez, 25/07/2004)

un quid en lugar de un quo, expresión de carácter gramatical usada para identificar un error en la escritura en latín. Por extensión se emplea para referirse a un error o confusión surgidos al expresarse.

quo vadis? (Gerard, 24/10/2004)

¿a dónde vas?, nombre de una famosa película basada en una obra literaria homónima. Sirve como pregunta retórica para introducir un cuestionamiento sobre el propósito, meta o sentido de una determinada acción.

rara avis (Rodríguez, 30/04/2004; Sagot, 13/06/2004)

ave extraña, sintagma empleado para referirse a casos, situaciones o conductas extrañas.

requiem (Aguilar, 14/09/2004; Rebeca 20/09/2004)

descanse, denominación de piezas musicales de carácter funerario.

verbigracia (EKA, 10/05/2004)

por ejemplo, latinismo empleado para introducir la ejemplificación de una tesis.

versus (Díaz, 12/05/2004)

contra, preposición latina empleada para expresar la oposición o enfrentamiento entre sujetos, conceptos o elementos de la más diversa índole. 


\section{Latín político}

Comprende este registro una serie de frases, sentencias y expresiones venidas del latín que son usadas en el proceso de estudio, crítica y reflexión sobre las condiciones políticas de una comunidad.

e pluribus unum (Valembois, 08/06/2004)

de muchos, uno, frase usada para referirse a la unidad política de una comunidad.

homo economicus (sic, Feinzaig, 20/08/2004)

ser humano económico, sintagma nominal que sirve para aproximarse al ser humano desde su faceta económica.

in crescendo (Rodríguez, 11/10/2004)

aumentando, locución empleada para referirse al incremento de una situación.l

panem et circenses (Guardia, 19/10/2004)

pan y circo, expresión que alude a la manipulación del pueblo por parte del gobierno a satisfacer sus impulsos básicos, en particular, el apetito.

\section{Latín de la lógica y la argumentación}

a priori (Díaz, 30/04/2004)

desde el primerísimo momento, latinismo que sirve para identificar las tesis asumidas sin ser fundamentadas apropiadamente.

ad hominem (Chinchilla, 25/09/2004)

contra el hombre, nombre que identifica aquella falacia en la que se ataca y descalifica a una persona en lugar de sus argumentos o ideas.

post hoc, non propter hoc (Rodríguez, 02/07/2004)

después de esto, no a causa de esto, regla lógica para prevenir la categoría de falacias de causa falsa originadas en una sucesión temporal.

\section{Latín filosófico}

Otro de los ámbitos presentes es el latín filosófico, el cual no solo contribuye a expresar ideas de manera sintética y profunda, sino que contribuye a revestir a sus usuarios de autoridad y erudición.

Amicus Plato, sed magis amica veritas (Marín, 13/06/2004)

Platón es mi amigo, pero mi mayor amiga es la verdad, traducción latina de una famosa sentencia atribuida a Aristóteles.

primum movens (Rodríguez, 16/08/2004)

primer motor, sintagma nominal empleado para denominar al factor del que se genera el movimiento cósmico.

Se cierra este elenco de voces del mundo clásico con el grecismo micro, pequeño, empleado por Carlos Sojo el 29 de abril del 2004. 


\section{Bibliografía}

Campos-Vargas, H. (2008). Habeas corpus, ¿que tengas cuerpo? Parlamentaria. 16 (1), 257266.

Campos-Vargas, H. (2010a). El latín y el derecho. Káñina. 34 (1), 45-61.

Campos-Vargas, H. (2010b). Latinismos en la prensa costarricense: latín jurídico versus otros registros. Káñina. 34 (Especial), 31-35.

Campos-Vargas, H. (2012) Algunos latinismos empleados en la prensa escrita costarricense. Káñina. 36 (2), 45-55.

Quirós-Rodríguez, M.A. (2012). Latinismos y helenismos de la filología. Káñina. 36 (1), 139158.

Real Academia de la Lengua Española. (2001). Diccionario de la lengua española. (Tomo II). ( $2^{\mathrm{a}}$ ed.). Madrid: Espasa Calpe.

Real Academia de la Lengua Española. (2005). Diccionario panhispánico de dudas. Madrid: Santillana Ediciones Generales.

Segura-Munguía, S. (2003). Nuevo diccionario etimológico Latín-Español y de las voces derivadas. ( $1^{\mathrm{a}}$ reimp.). Bilbao: Universidad de Deusto. 
